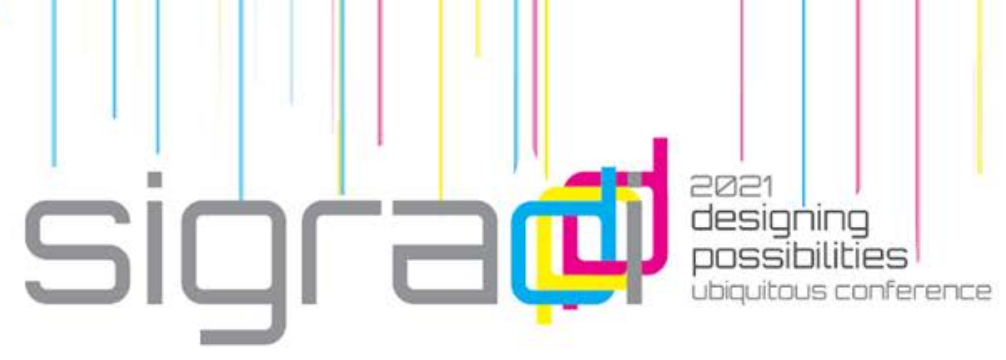

\title{
Tectonics and Computational Design Processes: Conceptual Perspectives
}

\author{
Ana Carolina Santos Vicente ${ }^{1}$, Denise Mônaco dos Santos ${ }^{1}$ \\ ${ }^{1}$ Universidade Federal de Viçosa, Brasil \\ ana.c.vicente@ufv.br \\ denise.monaco@ufv.br
}

\begin{abstract}
The concept of tectonics in architecture has evolved constantly in the past two centuries, but since the beginning of the "Digital Era" these theoretical changes have gained substance, and the term has been called "digital tectonics". There is still uncertainty, however, whether this new approach within computational process maintains the seminal poetical aspect of Frampton's definition. This study examines the emerging meanings of digital tectonics in the context of the traditional perspective, considering the main authors and recently published papers. The results show that, despite few arguments in favor of the contradiction between the words tectonics and digital, there are many similarities in the way the tectonics elements are manipulated in both the traditional and computational design processes. The insights gained from this study may be of assistance to discussions regarding the role of tectonics in the design thinking in the context of computational logics and digital fabrication.
\end{abstract}

Keywords: Tectonics, digital tectonics, computational design process, design theory, architectural technology.

\section{Introdução}

A principal noção da tectônica na teoria da arquitetura contemporânea foi definida por Kenneth Frampton (1996) como o "potencial de expressão construtiva da arquitetura", capaz de unir os aspectos materiais e construtivos aos culturais e estéticos. A discussão ganhou evidência no âmbito dos processos computacionais de projeto a partir do crescimento da inter-relação entre tecnologias digitais e design, no que tange à materialidade (integração dos materiais como base de projeto) e à associação das lógicas de fabricação digital (Oxman, 2017; Velasco \& Salgado, 2020). 
Sabe-se que o design computacional e a fabricação digital oferecem a possibilidade de se projetar com os materiais desde os primeiros estágios do processo de projeto, incorporando dados não só da aparência física, como sua textura, mas de suas propriedades e desempenhos mecânicos e até físicoquímicos, dispondo alto grau de informação da matéria, e dos sistemas estruturais e construtivos (Andersson \& Kirkegaard, 2006; Picon, 2013; Oxman, 2017; Santos \& Paoletti, 2020; Velasco \& Salgado, 2020).

Nesse sentido, a chamada "tectônica digital" configura uma metodologia de projeto orientada para processos com incorporação de dados materiais em ferramentas de geração formal, simulação, análise, otimização e fabricação (Al-Alwan \& Mahmood, 2020; Baliński \& Januszkiewicz, 2016; Santos \& Paoletti, 2020). Entende-se, assim, que os aspectos tecnológicos computacionais possivelmente modificaram a concepção da tectônica nos processos de projeto. Em vista disso, indaga-se se o conceito fundante da tectônica, na teoria da arquitetura contemporânea, implementado por Frampton é ainda pertinente quando examinados os atuais processos computacionais de projeto?

Desta forma, objetiva-se examinar a noção de tectônica no design computacional buscando destacar suas singularidades frente à noção demarcada por Frampton. Apresenta os resultados parciais de uma pesquisa maior, em andamento, que pretende apontar a natureza ímpar do componente tectônico nos processos computacionais de projeto.

A realização do trabalho se apoiou em uma revisão de literatura não apenas das obras clássicas acerca da tectônica, especialmente as de Frampton, mas considerou artigos que discutem a tectônica digital, e seus elementos, com foco no intervalo dos últimos 5 anos. Estes foram selecionados a partir da busca pelos termos "tectônica digital" e "tectônica + digital", em português e inglês, nos repositórios de artigos acadêmicos CUMINCAD, Web of Science e Google Acadêmico, e também em revistas e periódicos de relevância internacional na área, como Architectural Design, Design Studies, Procedia Engineering, Architectural Science Review, entre outros.

\section{A Tectônica Antes do Digital}

O termo "tectônica" é derivado etimologicamente da palavra grega tékton, que significa carpinteiro ou construtor, e de acordo com Kenneth Frampton (2006) esse conceito evolui para um significado mais amplo do fazer, que envolve a ideia da poiésis, quando aparece em Homero, aludindo à arte da construção em geral. Somado a isso, Adolf Borbein (1982 apud Frampton, 1996) argumenta que o termo adquire um caráter estético quando se torna a arte das junções e extrapola a funcionalidade, abrangendo a noção da tékhne, que derivada do grego tikto (produzir), implica a simultaneidade entre arte e ofício. 
Desta forma, a tékhne envolve um saber fazer adquirido por meio do aprendizado e da experiência (Frampton, 1996; Kim, 2006).

Apesar de se encontrar definições da tectônica nos escritos franceses dos séculos XVII e XVIII como "relativo à construção", foi na Alemanha, entre as décadas de 1830 e 1860, que o termo foi reformulado em um debate iniciado por Karl F. Schinkel e melhor desenvolvido por Karl Bötticher e Gottfried Semper como uma resposta à afirmação, sugerida por filósofos, de que a arquitetura guiada pela função era uma arte inferior à pintura, escultura e música (Frampton, 2006; Schwartz, 2017). Além disso, o desenvolvimento e utilização de novas técnicas estruturais e materiais, como o ferro e o vidro, motivou uma renovação teórica, inclusive da tectônica (Puig \& Bruscato, 2020).

$\mathrm{O}$ arquiteto Karl Bötticher (1806-1889) na obra "Tektonik der Hellenen" (1843-1852) referiu-se à tectônica como um sistema projetual em que se articula função, construção e a percepção relacionada às forças mecânicas da arquitetura, que garante não só o acabamento material de um edifício, mas também permite seu reconhecimento como forma simbólica (Frampton, 2006; Mallgrave, 2017; Schwarzer, 2017). Uma de suas maiores contribuições para a teoria foi a distinção entre a Kernform, ou forma nuclear, que constitui as formas utilitárias e conforma a essência estrutural do edifício, e a Kunstform, ou forma artística, que consiste no revestimento decorativo cuja finalidade é revelar simbolicamente a substância do edifício. Assim, para Bötticher, a tectônica é a coesão entre as dimensões operativas e simbólicas da edificação que faz com que a arquitetura transcenda o caráter pragmático da construção (Frampton, 1996; Frampton, 2006; Schwarzer, 2017).

No mesmo período, o arquiteto Gottfried Semper (1803-1879) em "Die vier Elemente der Baukunst" (1851) acrescenta uma dimensão antropológica à noção da tectônica ao concluir que a arquitetura se desenvolveu a partir de quatro motivos, que se relacionam diretamente a técnicas produtivas: a lareira (símbolo da socialização humana) se relaciona à cerâmica; o aterro está ligado à alvenaria; o telhado à carpintaria, e a envoltória às técnicas têxteis (Frampton, 1996; Mallgrave, 2017; Schwarzer, 2017). Após essa sistematização, Semper classifica as formas construídas a partir de dois procedimentos: a tectônica da estrutura, lógica construtiva que combina materiais variados e leves (como madeira, vidro e metal) para formar matrizes espaciais, e a estereotômica da massa comprimida, que consiste no empilhamento repetitivo de elementos pesados e homogêneos (como pedra, terra e concreto). Portanto, para ele, a tectônica é a expressão cultural gerada pela relação entre formas, materiais e técnicas na arquitetura (Al-Alwan \& Mahmood, 2020; Frampton, 2006; Mallgrave, 2017; Schwarzer, 2017).

Dessa forma, o discurso da tectônica do século XIX marcou um momento de transição na disciplina, ao transformar a tradição clássica através da integração de ciências modernas como tecnologia, história da arte e estética (Schwartz, 2017; Schwarzer, 2017). Além disso, a definição do termo como "pertinente à construção em geral" é considerada redutiva para Frampton (2006), visto que indica, nas teorias de Bötticher e Semper, não só a 
honestidade material e estrutural, mas também uma poética do construir que eleva a arquitetura a uma forma artística.

Pouco mais que um século depois, em 1965, no ensaio "Structure, Construction, Tectonics" Eduard Sekler (1920-2017) conceitua a tectônica a partir das definições de estrutura e construção. Para ele, a estrutura é uma noção mais abstrata que se refere a concepção e avaliação da eficiência dos sistemas estruturais em que operam as forças atuantes de um edifício. Já a construção é a realização desses sistemas, através da escolha e manuseio dos materiais, dos processos e das técnicas possíveis. A tectônica, por sua vez, é o fenômeno expressivo que resulta da integração entre as lógicas estrutural e construtiva na constituição arquitetônica. Dessa forma, o potencial tectônico depende do equilíbrio e articulação entre as partes e elementos de sua formação, e sua expressividade pode ser exagerada, indefinida ou até inexistente, que configura o que Sekler chamou de atectônica, quando a construção não reflete o princípio estrutural (Frampton, 1996; Sekler, 1965).

Então, no final do século XX a noção da tectônica é reintroduzida por Kenneth Frampton (1930-) como uma alternativa de resistência à homogeneização do ambiente construído da arquitetura moderna e à tendência cenográfica da arquitetura pós-moderna. Assim, ele busca a reaproximação da arquitetura com o contexto cultural em que se insere e afirma que a essência da edificação é dotada de caráter tectônico, que é um ato de construção e não um discurso baseado em plano, superfície e volume (Frampton, 1996; Frampton, 2006; Nesbitt, 2006; Puig \& Bruscato, 2020).

O estudo de Frampton (1996) busca enriquecer a discussão acerca do espaço arquitetônico através da reconsideração do potencial expressivo dos elementos estruturais e construtivos, que conformam a tectônica enquanto poética, logo, enquanto uma arte que não é figurativa e nem abstrata, mas que comunica. O autor, influenciado pela fenomenologia de Heidegger, argumenta que os arquitetos podem se voltar à tectônica como a essência da arquitetura, capaz de expressar sua relação com o mundo, cuja manifestação poética, no sentido da poiésis, se dá na integração entre o fazer, o conhecer e o revelar (Frampton, 2006; Nesbitt, 2006). Para Frampton, como a arquitetura está em uma posição entre a percepção humana e a tecnologia, a tectônica se apresenta como um meio que diferencia esses dois estados, subjetividade e objetividade, e seu potencial advém de sua capacidade de articular esses estados em um edifício. Então, ele argumenta que a prática arquitetônica deve estar fundamentada em seus procedimentos tectônicos, que envolvem a cultura local, e por isso não favorece a nenhum estilo ou época específicos, sendo atemporal por definição (Frampton, 1996).

Com tudo isso, entende-se que Kenneth Frampton popularizou a discussão sobre a tectônica na teoria da arquitetura contemporânea, e considera-se que sua obra "Studies in Tectonic Culture" (1996) é a mais importante acerca do assunto, tendo motivado e embasado as abordagens e trabalhos que sucederam sua publicação. Logo, pode-se dizer que a sua definição da tectônica, como a poética da construção que comunica de forma integrada os 
aspectos técnicos, materiais, culturais e de expressividade da arquitetura, é a mais consolidada do termo, e por isso, seu ponto de vista será considerado como a base das discussões no presente artigo.

\subsection{Elementos}

De acordo com Schwartz (2017) a constante evolução da teoria da tectônica resultou organicamente em diversas linhas de pensamento. Então, a partir da contribuição seminal de Frampton e com o objetivo de compreender e comunicar melhor o que compõe a tectônica, muitos autores se propuseram a classificá-la taxonomicamente, através da exploração de seus elementos fundantes.

Segundo Liu e Lim (2006) os principais componentes tectônicos na arquitetura são: Objeto (consiste nas partes que formam o edifício como um todo); Detalhe (sugere as relações entre as partes e o todo); Junção (une e articula as diferentes partes, materiais e componentes do edifício); Material (constitui a formação e composição da construção); Estrutura (lógica da transição de forças); Construção (realização hierárquica da concepção estrutural); Interação (trata das relações entre o lugar, as pessoas e a arquitetura, através de variáveis geográficas e/ ou da percepção sensorial).

$\mathrm{Na}$ abordagem de Schwartz (2017) os elementos que compõem e possibilitam a análise da tectônica são: Anatomia (componentes primários da edificação); Construção (sistemas, métodos construtivos e a materialidade do ambiente construído); Detalhe (junção dos diferentes elementos e sistemas que conformam significação); Lugar (papel do contexto, material ou imaterial, na formação tectônica); Representação + Ornamentação (comunicação visual do propósito utilitário do edifício); Espaço (relações entre os arranjos espaciais e os materiais e técnicas utilizadas na construção); Atectônica (distorção proposital da expressão tectônica no edifício ou no espaço).

Al-Alwan e Mahmood (2020) sistematizam os principais elementos no que chamam de "tríade da tectônica", que consiste em: Técnica (configura a interrelação entre construção, tecnologia e representação); Cultura (consiste na relação entre a arte e a manufatura artesanal); Material (relaciona estrutura, ciência e ontologia). Já Puig e Bruscato (2020) argumentam que os elementos que resumem a tectônica são: Estrutura (sistema que lida com as forças atuantes na edificação); Construção (operacionalização do sistema estrutural); Material (componentes construtivos).

A partir do exame de trabalhos que procuraram eleger possíveis elementos da tectônica tem-se uma possível síntese, como aparece na figura 1. Observase que detalhe, material, estrutura e construção são componentes comuns entre as sistematizações e por isso, acredita-se que podem ser o ponto de partida caso a unificação das propostas seja desejada. 
imaterial, abstrato, em constante atualização, que tenderia à dimensão virtual do ambiente construído (Andersson \& Kirkegaard, 2006). Entretanto, Yan e Yuan (2021) argumentam que, no campo arquitetônico por excelência, o termo "tectônica digital" emerge dos esforços de mediar essa "dualidade" entre a tectônica, que apresenta uma demanda pela autenticidade da forma construída, e o digital, que explora novas compreensões da própria materialidade. Para esses autores, a tectônica digital busca justamente uma reconexão entre arquitetos e a instância da construção, através da exploração dos processos de projeto computacionais baseados nas capacidades de modelar as propriedades materiais dos componentes construtivos.

Em 2004 Neil Leach, David Turnbull e Chris Williams já buscavam dissolver a contradição entre os termos destacando o potencial tectônico, ligado à digitalidade, a ser explorado também pela capacidade das ferramentas computacionais em buscar as mais eficientes soluções relacionadas às questões estruturais, construtivas ou ambientais (Al-Alwan \& Mahmood, 2020). Nesse sentido, constrói-se um entendimento de que a tectônica digital diz respeito à exploração das possibilidades de combinar a morfologia desenvolvida com as ferramentas computacionais diretamente com as propriedades materiais, associadas a elementos construtivos, em um processo bottom-up, de maneira que as mudanças nos aspectos ontológicos são manifestadas nos expressivos e vice-versa (Yan \& Yuan, 2021). Em resumo, a tectônica digital para Leach, Turnbull e Williams diz respeito à expressão tectônica que se estabelece a partir de processos computacionais envolvendo geração, simulação e otimização formal com dados materiais associados.

Beesley e Seebohm (2000) caracterizam a tectônica digital a partir da utilização sistemática, através de processos generativos, de ordenações geométricas combinadas a componentes construtivos como detalhes e junções. As técnicas utilizadas nesses processos para Gao (2004) não são apenas ferramentas de projeto, mas produzem as lógicas que configuram as formas e seus relacionamentos complexos. Todos esses autores definem a tectônica digital como uma metodologia de projeto que integra, por meio do computador, o design digital às técnicas construtivas tradicionais.

Por outro ponto de vista, Jabi (2004, p. 267, tradução das autoras) considera que o surgimento dos processos de fabricação digital permitiu a oportunidade de explorar uma nova tectônica, definida como “... a poética da arquitetura concebida digitalmente, clarificada estruturalmente e fabricada diretamente...". Indo além, Oxman (2012) introduz o termo "tectônica informada" para caracterizar processos de projeto e de produção em que a tectônica digital pode ser tomada como um aspecto caracterizador de processos form-finding, paramétricos e/ou algorítmicos, em que a performance dos materiais associados a elementos construtivos está em primeiro plano, podendo ser auxiliada pela produção computadorizada. Em complemento, Veliz Reyes et al. (2019) argumentam que a fabricação digital pode amplificar o caráter expressivo da tectônica digital ao permitir a evolução síncrona dos aspectos digitais e físicos da arquitetura. 
Outras abordagens definem a tectônica digital como um processo em que há a integração de aspectos formais e estruturais não só através das ferramentas, mas das lógicas de projeto computacionais. Al-Alwan e Mahmood (2020) afirmam que a noção vai além da inclusão de tecnologias digitais, sendo um procedimento que integra os aspectos estéticos, técnicos, abstratos e concretos da arquitetura. Essa definição é complementada pela perspectiva de Santos e Paoletti (2020, p. 19, tradução das autoras) de que a tectônica digital constitui a associação de dados materiais a ferramentas de "...geração, simulação, análise, otimização e fabricação".

Por fim, a tectônica digital de Schumacher (2017) se aproxima das definições anteriores, por ser um princípio em que as lógicas de engenharia e fabricação participam ativamente na formação e articulação tectônica, através de processos de form-finding e otimização. Porém, sua visão estilística da tectônica, denominada "Tectonismo", contraria o fundamento proposto por Frampton de que a tectônica não conforma nenhum estilo arquitetônico, e sim é parte inerente a toda arquitetura.

\subsection{Elementos}

A partir do desenvolvimento das tecnologias CAD e CAM, e da discussão em relação à teoria da tectônica nos processos computacionais de projeto, alguns autores se propuseram a identificar os elementos que compõem a noção da "tectônica digital".

Gao (2004) levantou os aspectos mais relevantes que a caracterizam: Conceito (integra movimento e ação das forças na estrutura); Manipulação (explora os parâmetros como estrutura, componentes construtivos e materiais que atuam na geração e formação do edifício); Construção (examina o estado informativo dos materiais e elementos construtivos como inputs paramétricos e que permitem a adaptabilidade); Forma (dotada de expressividade através da possibilidade da manipulação direta, ativa e imediata dos modelos digitais); Espaço (dotado de "vida" a partir da forma, que concebida digitalmente, enfatiza a interação entre o objeto e o usuário, através da comunicação sensorial).

Apesar de terem elencado os elementos da tectônica tradicional, Liu e Lim (2006) argumentam que estes não englobam os fenômenos da tectônica digital, e por isso propõem um conjunto específico de fatores: Manipulação (processo de operações dinâmicas da evolução conceitual e formal); Informação (utilização de dados digitais, obtidos através de simulações por exemplo, como um material na constituição de um edifício); Formação (emprego de sistemas paramétricos el ou algorítmicos no processo de desenvolvimento formal); Fabricação (método de produção e montagem dos componentes construtivos auxiliado pelas tecnologias CAM).

Al-Alwan e Mahmood (2020) resumem seus principais pontos na chamada "tríade da tectônica digital" que é composta por: Ferramenta (representada pelos programas digitais e aspectos técnicos); Articulação (consiste na 


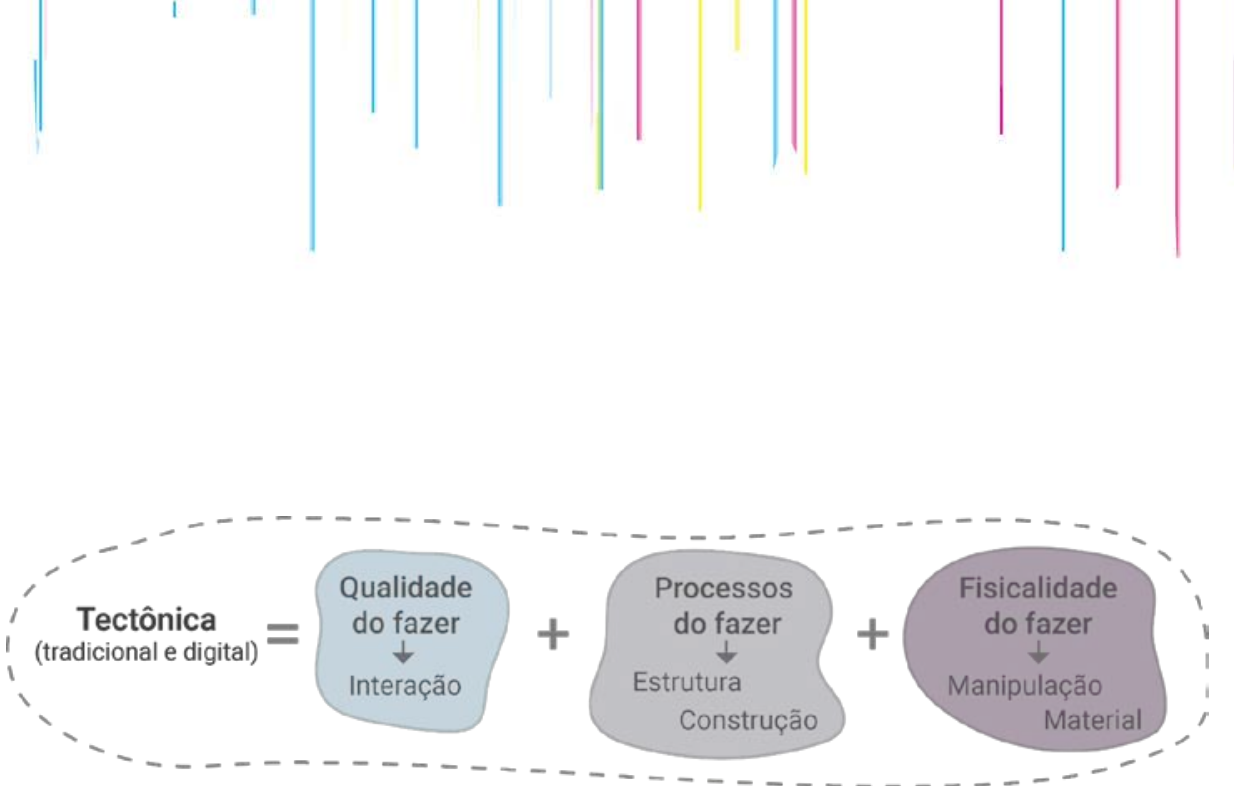

Figura 4. Sistematização das grandes áreas da tectônica. Fonte: Autoras.

síntese de cada uma, a saber: 1) Interação (ligada ao qualitativo do fazer, é o caráter poético e comunicativo da arquitetura que è inerente à tectônica e se relaciona ao contexto e às pessoas, mas que dependendo da intencionalidade do arquiteto pode ser exaltada ou mais discreta); 2) Estrutura e construção (estão relacionadas aos processos do fazer, desde a concepção até a realização, e dependendo das técnicas utilizadas incluem mais ou menos elementos); 3) Material e manipulação (se referem à materialidade do fazer, e apesar do material ser um aspecto similar, na tectônica digital suas propriedades são consideradas desde o início do processo de projeto, e muitas vezes determinam os modos do fazer).

\section{Considerações finais}

Ao longo das transformações sociais, culturais, econômicas e tecnológicas pelas quais a humanidade passou, a teoria tectônica também se modificou. Em relação à arquitetura, essas modificações foram influenciadas, principalmente, pelos desenvolvimentos não só de novos materiais, mas de novas técnicas construtivas e lógicas de pensamento de projeto, proporcionadas pelas capacidades computacionais dos novos processos e ferramentas.

Dessa forma, entende-se que, a partir das mudanças na prática arquitetônica, a teoria está em constante transformação, e por isso julgou-se necessária a revisão das diferentes abordagens da tectônica digital, tendo como base a teoria de Frampton, a fim de compreender seu desenvolvimento, e como resultado a divisão da tectônica em três grandes áreas, que relacionam aspectos das tectônicas tradicional e digital.

Logo, não há dúvidas de que os aspectos tecnológicos computacionais modificaram a manipulação da tectônica nos processos de projeto, mas acredita-se que a oposição entre a tectônica e o digital, proposta no final do séc. $X X$ não faz sentido em um contexto em que se trabalha a materialidade de maneira declarada, em que são feitas análises e simulações de condições ambientais reais, ou em que se criam novos materiais e técnicas construtivas, com o auxílio do computador.

Por fim, conclui-se que nos processos de projeto computacionais o arquiteto tem o domínio sobre os diversos elementos da tectônica em um sistema adensado, e que a tectônica possivelmente está em primeiro plano nesses 
Mallgrave, H. F. (2017). Gottfried Semper and Modern German Theory. In H. F. Mallgrave, M. Bressani, \& C. Contandriopoulos (Eds.), Companion to the History of Architecture: Vol. III (1st ed., pp. 1-22). John Wiley \& Sons, Inc. https://doi.org/10.1002/9781118887226.wbcha089

Nesbitt, K. (2006). Uma Nova Agenda Para a Arquitetura: Antologia Teórica 1965-1995 (1st ed.). Cosac Naify.

Oxman, R. (2012). Informed tectonics in material-based design. Design Studies, 33(5), 427-455. https://doi.org/10.1016/j.destud.2012.05.005

Oxman, R. (2017). Thinking difference: Theories and models of parametric design thinking. Design Studies, 52, 4-39. https://doi.org/10.1016/j.destud.2017.06.001

Picon, A. (2013). Architecture, innovation and tradition. Architectural Design, 83(1), 128133. https://doi.org/10.1002/ad.1535

Puig, R. J. F., \& Bruscato, U. M. (2020). Teoria Da Tectônica : Do Tradicional Ao Digital. Revista Brasileira de Expressão Gráfica, 8(2), 22-43. https://lume.ufrgs.br/handle/10183/217226

Santos, D. M. dos, \& Paoletti, I. (2020). Material-Based Design: Improving a Continuous Changing Praxis. XXIV International Conference of the Iberoamerican Society of Digital Graphics, 17-22. https://doi.org/10.5151/sigradi2020-3

Schwartz, C. (2017). A Taxonomy of Architectural Tectonics. In S. Doyle, T. Leslie, \& R. Whitehead (Eds.), Poetics and Pragmatism Proceedings: Papers Presented at BTES (Building Technology Educators' Society) (pp. 179-186).

Schwarzer, M. (2017). German Tectonics. In H. F. Mallgrave, M. Bressani, \& C. Contandriopoulos (Eds.), Companion to the History of Architecture: Vol. III (1st ed., pp. 1-13). John Wiley \& Sons, Inc. https://doi.org/10.1002/9781118887226.wbcha088

Sekler, E. F. (1965). Structure, Construction, Tectonics. In G. Kepes (Ed.), Structure in Art and in Science (pp. 89-95). George Braziller.

Velasco, V. E. S., \& Salgado, S. A. C. (2020). Digital Fabrication: an Outlook from Digital Tectonics. XXIV International Conference of the Iberoamerican Society of Digital Graphics, 3-8. https://doi.org/10.5151/sigradi2020-1

Veliz Reyes, A., Jabi, W., Gomaa, M., Chatzivasileiadi, A., Ahmad, L., \& Wardhana, N. M. (2019). Negotiated matter: a robotic exploration of craft-driven innovation. Architectural Science Review, 62(5), 398-408. https://doi.org/10.1080/00038628.2019.1651688

Yan, C., \& Yuan, P. F. (2021). Beyond Embodiment: An Existential Project of Digital Tectonics in the Posthumanist Discourses. In A. Globa, J. van Ameijde, A. Fingrut, N. Kim, \& T. T. S. Lo (Eds.), PROJECTIONS - Proceedings of the 26th CAADRIA Conference (Vol. 2, pp. 91-100). http://papers.cumincad.org/cgibin/works/paper/caadria2021_162 